\title{
Advances in molecular mechanisms of heavy metal induced cell malignant transformation
}

\author{
Yi Liu ${ }^{1,2}$, Miaomiao Tang ${ }^{1,2}$, Zhongping Zhou ${ }^{1,2}$, Haifeng Shi ${ }^{1}$ and Jian Lu ${ }^{1,2 *}$ \\ ${ }^{1}$ Institute of Life Sciences, Jiangsu University, Zhenjiang, China \\ ${ }^{2}$ School of Medicine, Jiangsu University, Zhenjiang, China
}

\begin{abstract}
Chronic exposure to heavy metal is a worldwide health concern for many diseases: hematologic diseases, neurological disorders, Immune diseases and cancer. Cancer is commonly considered to be developed from malignantly transformed cells. Malignant cell transformation is also the pivotal process of carcinogenesis induced by heavy metal, but the mechanisms of heavy metal in cell malignant transformation remain to be elucidated, especially in ROS generation, cell proliferation, migration and invasion, inflammation, angiogenesis, cancer stem-like cells accumulation and autophagy. To achieve more comprehensive and in-depth understanding of heavy metal induced carcinogenesis, this review summarizes some recent advances which are mostly biological characteristics and processes involved in heavy metal induced cell malignant transformation.
\end{abstract}

\section{Introduction}

Exposure to heavy metals of human beings is a major public health concern. Heavy metals here refer to a diverse group of high-molecularweight inorganic chemical elements with or without radiation, such as chromium, arsenic, cadmium, nickel and so on [1]. They are universally present in the water, soil, food, and even in the air. Industrial processes as well as their widespread usages have given rise to environmental heavy metal exposure of human [2]. Correspondently, heavy metals have been conventionally regarded as human carcinogens for their malignant transformation. Long-term exposure to inorganic heavy metal of normal cells can lead to a malignant cell transformation [3]. Chronic exposure to hexavalent chromium and trivalent arsenic are able to cause malignant transformation in human bronchial epithelial (BEAS-2B) cells [4], demonstrated by the anchorage-independent growth of cells. Cadmium exposed Beas-2B cells also show many differences in cytotoxicity, morphology, cell viability and proliferative potential compared with normal BEAS-2B cells [5]. Epidemiological studies show a close relationship between nickel exposure and an increased risk of lung and nasal cancers [6]. Although the transformation induced by heavy metal is well known, the underlying mechanisms are proved to be ambiguous and various. Thus, we need to dig in the molecular mechanisms of cell malignant transformation by heavy metals via the changes of physiological and biochemical characteristics in the progression of such transformation.

\section{Generation of reactive oxygen species (ROS)}

Among various mechanisms proposed, the generation of reactive oxygen species seems to be the most common. It seems to be universally recognized that ROS have the carcinogenic potential and are associated with tumorigenesis and subsequent progression [7]. When the ROS contained in the cellular system overpower the defense system, which is composed of various antioxidants with different functions, they will give rise to cell injuries, and corresponding diseases, including tumor [8]. Most carcinogenic metals have been manifested to produce a whole spectrum of ROS, such as the superoxide anion radical
(O2.-), hydrogen peroxide $\left(\mathrm{H}_{2} \mathrm{O}_{2}\right)$ and hydroxyl radical $(\cdot \mathrm{OH})$ [9]. Study shows that hexavalent chromium exposure stimulated O2-and $\mathrm{H}_{2} \mathrm{O}_{2}$ generation in BEAS-2B cells, as indicated by an increase of DHE and DCFDA fluorescence intensity, compared to those generated from untreated control cells [3]. Both long-term and shortterm exposure of chromium induce the generation of ROS and the expression of NOX subunits, such as $\mathrm{p} 47^{\text {phox }}$ and $\mathrm{p} 67^{\text {phox }}$ [10]. Studies have also demonstrated that inhibition of ROS by CAT (antioxidant against $\mathrm{H}_{2} \mathrm{O}_{2}$ ) and SOD (antioxidant against $\mathrm{O} 2 \cdot-$ ) decreases arsenicinduced cell transformation [11]. Though great contributions to cell transformation progress that ROS have made, it is interesting that the basal level of ROS of transformed cells is extremely low. Data shows that transformed cells exhibit a sharply decreased capability of ROS generation [12]. The decreased production of ROS causes some of the malignant features, such as fast growth, apoptosis resistance, and anchorage-independent growth [8]. Taken together, ROS plays a dual role in the process of malignant cell transformation.

\section{Induction of migration and invasion}

Migration, one of the major characteristics of malignantly transformed cells, contributes to the high mortality of cells [13], and so does invasion. Numerous researches have revealed some potential relationships between malignant cell transformation and migration along with invasion. Report displays that arsenic-induced BEAS-2B cells have the ability of motility and can be suppressed by apigenin via

Correspondence to: Jian $\mathrm{Lu}$, Institute of Life Sciences, Jiangsu University, Zhenjiang, China and School of Medicine, Jiangsu University, Zhenjiang, China, Tel: 8613815178967; E-mail: lujian@ujs.edu.cn

Key words: heavy metal, malignant cell transformation, ROS, migration and invasion, inflammation, angiogenesis, apoptosis resistance, cancer stem-like cells, autophagy

Received: December 18, 2017; Accepted: December 29, 2017; Published: January 02, 2018 
wound healing migration assay and Boyden chamber invasion assay [13]. Previous study demonstrated that chronic hexavalent chromium exposure to BEAS-2B cells results in malignant transformation as assessed by increased anchorage independent growth in soft agar [14]. Similar results were observed with the colony formation assay. Hexavalent chromium exposure can dramatically increase the number of colonies [15]. Matrix metalloproteinases (MMPs), highly expressed in many cancers, are generally recognized to be closely associated with invasive tumor growth and its migration [16]. Many studies have discovered the overexpression of MMPs in the heavy metaltransformed cells compared to the normal untransformed cells $[15,17]$. Other biological molecules like this are vascular endothelial growth factor (VEGF), hypoxia-inducible factor-1 (HIF-1), epidermal growth factor receptor (EGFR) and so on. There are not too many evidences solely concerning migration and invasion, and mostly are studied with angiogenesis, for example, VEGF is also crucial for angiogenesis.

\section{Induction of inflammation}

Chronic inflammation is one of the key elements associated with carcinogenesis. Study reveals that repetitive exposure to hexavalent chromium results in persistent inflammation, and such an inflammatory microenvironment can further promote carcinogenesis [18]. There are evidences showing that inflammation is implicated in hexavalent chromium-induced human lung cancer development [19]. Proinflammatory cytokines, including interleukin- $1 \beta$ (IL-1 $\beta$ ), interleukin-6 (IL-6), interleukin-8 (IL-8) and tumor necrosis factor-alpha (TNF- $\alpha$ ) are involved in several pathological processes [20], and chronic hexavalent chromium exposure leads to an elevated production of these pro-inflammatory cytokines in BEAS-2B cells [15]. The activation of cyclooxygenase-2 (COX-2) is also associated with inflammation and carcinogenesis [21], and an elevated COX-2 expression has been demonstrated in hexavalent chromium-exposed cultured cells [21]. Meanwhile, STAT3 is linked to inflammation-associated oncogenic cell transformation by promoting pro-oncogenic inflammatory pathways, including nuclear factor- $\kappa \mathrm{B}(\mathrm{NF}-\kappa \mathrm{B})$ and interleukin-6 (IL-6) [22]. To sum up, inflammation is a common and indispensable feature in the progress of malignant cell transformation, paving the way for the subsequent carcinogenesis.

\section{Guidance of cell proliferation, cell survival and apopto- sis resistance}

The temination of malignant transformed cells is to achieve immortalization, during which the cells gradually possess the ability of unlimited proliferation and enhanced cell viability, which means apoptosis resistance. Researches show that nickel-transformed cells proliferated faster than control cells which were not exposed [23]. Chronic treatment of human bronchial epithelial BEAS-2B cells with low doses of nickel chloride resulted in cell transformation demonstrated by increased cell growth and alterations of cell growth pattern [23]. In addition, two major anti-apoptotic proteins of the $\mathrm{Bcl}$ family, Bcl-2 and Bcl-XL, are increased in nickel-transformed cells [23]. In the trivalent arsenic-induced BEAS-2B cells, nuclear factor erythroid 2-related factor (Nrf2) and p62 are constitutively expressed, which up-regulates the anti-apoptotic proteins, Bcl-2 and Bcl-XL [24].

Accumulating evidences also suggest that microRNAs-mediated signaling pathway plays a significant role in cell proliferation, cell survival and apoptosis resistance. In the trivalent arsenic-transformed cells an increased level of miR-190 can be detected, and overexpression of miR-190 (microRNA-190) itself is able to enhance proliferation and malignant transformation of the cells [25]. Study indicates that arsenic exposure induced an upregulation of miR-21(microRNA-21) expression associated with inhibition of PDCD4, and caused malignant cell transformation and tumorigenesis of BEAS-2B cells [26].

The signal transducer and activator of transcription-3 (STAT-3) has been observed in many human cancers and implicated in tumor cell survival, proliferation, invasion, as well as angiogenesis [27,28]. Indispensably, STAT3 transcriptional activation by IL-6 is crucial for the arsenic induced miR-21 increase [26]. Stable shut down of STAT3 in BEAS-2B cells markedly inhibited the arsenic induced malignant transformation and tumorgenesis [26].

\section{Promotion of angiogenesis}

Angiogenesis, the formation of new blood vessels from existing vasculature, is essential for tumor initiation and progression[29]. Data shows that hexavalent chromium-transformed cells are angiogenic [17]. It was observed that epidermal growth factor receptor(EGFR) is constitutively activated in hexavalent chromium-transformed human bronchial epithelial BEAS-2B cells, which is a positive regulator of angiogenesis [30]. Study shows that expressions of angiogenetic factors interleukin-6(IL-6) and MMP-1 are increased in hexavalent chromium-transformed cells compared with passage-matched normal cells. The mRNA levels of these genes are also up-regulated in these cells [17]. Angiogenesis is also considered to be one of the basic conditions for tumor metastasis which is mainly mediated by HIF-1, VEGF, and MMPs. Study elucidated that protein expression levels of HIF-1a, MMP-9, and VEGF are increased markedly with chronic hexavalent chromium exposure [15].

\section{Accumulation of cancer stem-like cells}

Accumulation of cancer stem-like cells in metal carcinogenesis is not very common, still, some studies indicate that the generation of cancer stem cells might contribute to the overall mechanism of development of metal-induced cancer [31]. Malignant tumors often arise from a small subset of stem-like cells. These cells are able to develop into cancer stem-like cells when exposed to environmental heavy metals, leading to a carcinogenic process [32]. Cells acquisition of stem-like properties during carcinogenesis may be attributable to many factors, including DNA damage caused by ROS, signaling transduction induced by metals, inflammatory responses originating from metal exposure, and EMT [33]. Cancer stem-like cells were enriched in nickel-transformed cell (BNiT) population, and the transformed cells demonstrated enhanced self-renewal and distinctive differentiation properties [34].

\section{Provoking of autophagy}

Autophagy is a catabolic process in which intracellular longlived proteins and dysfunctional organelles, such as mitochondria, are sequestered in autophagosomes and subsequently degraded by lysosomal machinery [35]. Trivalent arsenic-induced cells have autophagy deficiency as evidenced by reduced formation of microtubule-associated protein 1 light chain 3(LC3)-II, GFP-LC3 puncta, and autophagy flux [24]. It is also reported that cadmiumtransformed cells have acquired autophagy deficiency leading to constitutive p62 and Nrf2 overexpression, which finally decreases in ROS generation, apoptotic resistance, and increases cell survival, proliferation, and tumorigenesis [36]

\section{Summary}

It has been universally acknowledged that heavy metals take active parts in carcinogenesis, by means of cell damage as well as malignant 


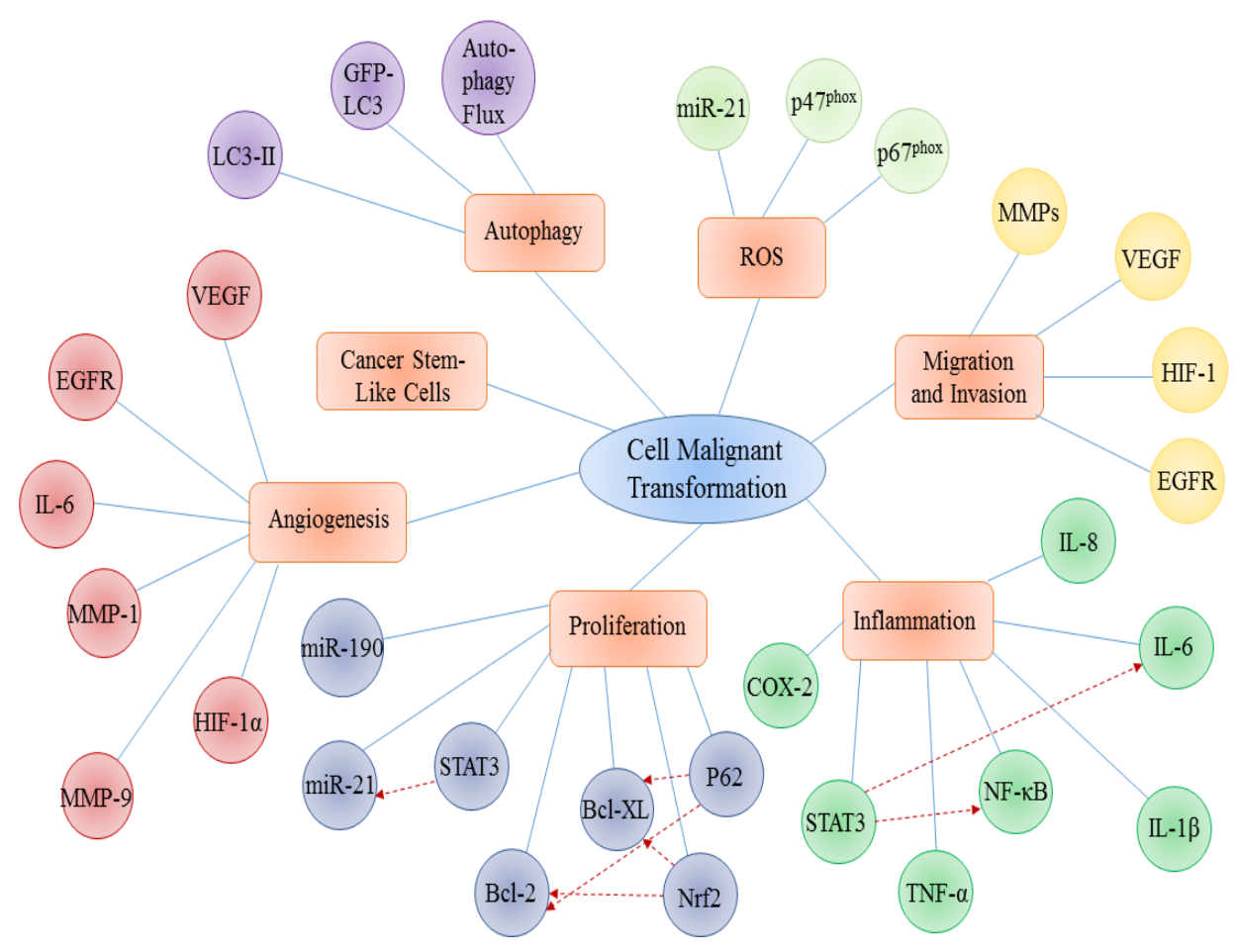

Figure 1. Main molecular mechanisms involved in heavy metal induced malignant cell transformation

cell transformation. Increasing evidences illustrate that heavy metal such as chromium, arsenic, cadmium and nickel are able to transform normal cells into cancer-like cells, indicated by morphology and dynamics results. In this review, advances of molecular mechanisms on heavy metal induced malignant cell transformation are summarized from several fundamental biological processes: ROS generation, migration and invasion, inflammation, cell proliferation, angiogenesis, accumulation of cancer stem-like cells, and autophagy. Many of the mechanisms contribute to malignant cell transformation, yet they are not isolated. More than one mechanism mentioned above co-regulates the process of cell malignant transformation, forming a regulatory network, which implies that malignant cell transformation by heavy metal is not induced in a single and explicit way, but a multiple and elusive one (Figure 1).

\section{References}

1. Wang L, Wise JT, Zhang Z, Shi X (2016) Progress and Prospects of Reactive Oxygen Species in Metal Carcinogenesis. Curr Pharmacol Rep 2: 178. [Crossref]

2. Yang MA (2011) Current Global View of Environmental and Occupational Cancers. $J$ Environ Sci Health C 29: 223.

3. Pratheeshkumar P, Son YO, Divya SP, Turcios L, Roy RV, et al. (2016) Hexavalent chromium induces malignant transformation of human lung bronchial epithelial cells via ROS-dependent activation of miR-21-PDCD4 signaling. Oncotarget 7: 51193 51210. [Crossref]

4. Zhang Z, Pratheeshkumar P, Budhraja A, Son YO, Kim D, et al (2015) Role of reactive oxygen species in arsenic-induced transformation of human lung bronchial epithelial (BEAS-2B) cells. Biochem Biophys Res Commun 456: 643-648. [Crossref]

5. Son YO, Pratheeshkumar P, Roy RV, Hitron JA, Wang L, et al. (2014) Nrf2/p62 signaling in apoptosis resistance and its role in cadmium-induced carcinogenesis. $J$ Biol Chem 289: 28660-28675. [Crossref]

6. Leonard SS, Bower JJ, Shi X (2004) Metal-induced toxicity, carcinogenesis, mechanisms and cellular responses. Mol Cell Biochem 255: 3-10.

7. Ames BN (1988) Measuring oxidative damage in humans: relation to cancer and ageing. Iarc Scientific Publications 89: 407.
8. Zhang Z (2015) Role of reactive oxygen species in arsenic-induced transformation of human lung bronchial epithelial (BEAS-2B) cells. Biochemical \& Biophysical Research Communication 456: 643-648.

9. Lee JC, Son YO, Pratheeshkumar P, Shi X (2012) Oxidative stress and metal carcinogenesis. Free Radic Biol Med 53: 742-757. [Crossref]

10. Li N, Alam J, Venkatesan MI, Eiguren-Fernandez A, Schmitz D, et al. (2004) Nrf2 is a key transcription factor that regulates antioxidant defense in macrophages and epithelial cells: protecting against the proinflammatory and oxidizing effects of diesel exhaust chemicals. J Immunol 173: 3467-3481. [Crossref]

11. Pooya S, Liu X, Kumar VB, Anderson J, Imai F, et al. (2015) Corrigendum: The tumour suppressor LKB1 regulates myelination through mitochondrial metabolism. Nat Commun 6: 6075. [Crossref]

12. Chang Q, Pan J, Wang X, Zhang Z, Chen F, et al. (2010) Reduced reactive oxygen species-generating capacity contributes to the enhanced cell growth of arsenictransformed epithelial cells. Cancer Res 70: 5127-5135. [Crossref]

13. Wang L, Kuang L, Hitron JA, Son YO, Wang X, et al. (2013) Apigenin suppresses migration and invasion of transformed cells through down-regulation of C-X-C chemokine receptor 4 expression. Toxicol Appl Pharmacol 272: 108. [Crossref]

14. Wang X (2011) NADPH Oxidase Activation Is Required in Reactive Oxygen Species Generation and Cell Transformation Induced by Hexavalent Chromium. Toxicol Sci 123: 399. [Crossref]

15. Pratheeshkumar P, Son YO, Divya SP, Roy R, Hitron JA, et al. (2014) Luteolin inhibits $\mathrm{Cr}(\mathrm{VI})$-induced malignant cell transformation of human lung epithelial cells by targeting ROS mediated multiple cell signaling pathways. Toxicol Appl Pharmacol 281: 230-241. [Crossref]

16. Gordon MS, Mendelson DS, Kato G (2010) Tumor angiogenesis and novel antiangiogenic strategies. Int J Cancer 126: 1777-1787. [Crossref]

17. Kim D, Dai J, Park Y, Fai LY, Wang L, et al. (2016) Activation of EGFR/p38/HIF-1o is pivotal for angiogenesis and tumorigenesis of malignantly transformed cells induced by hexavalent chromium. J Biol Chem.

18. Beaver LM, Stemmy EJ, Constant SL, Schwartz A, Little LG, et al. (2011) Lung injury, inflammation and Akt signaling following inhalation of particulate hexavalent chromium. Toxicol Appl Pharmacol 235: 47-56. [Crossref]

19. Zuo Z, Cai T, Li J, Zhang D, Yu Y, et al. (2012) Hexavalent Chromium Cr(VI) UpRegulates COX-2 Expression through an NFkappaB/c-Jun/AP-1-Dependent Pathway. Environ Health Perspect 120: 547-553. 
20. Bouraoui Y, Ricote M, García-Tuñón I, Rodriguez-Berriguete G, Touffehi M, et al. (2008) Pro-inflammatory cytokines and prostate-specific antigen in hyperplasia and human prostate cancer. Cancer Detect Prev 32: 23-32. [Crossref]

21. Hakozaki M (2014) Overexpression of cyclooxygenase-2 in malignant peripheral nerve sheath tumor and selective cyclooxygenase- 2 inhibitor-induced apoptosis by activating caspases in human malignant peripheral nerve sheath tumor cells. Plos One 9: e88035.

22. Yu H, Pardoll D, Jove R (2009) STATs in cancer inflammation and immunity: a leading role for STAT3. Nat Rev Cancer 9: 798-809. [Crossref]

23. Pan JJ, Chang QS, Wang X, Son YO, Liu J, et al. (2011) Activation of Akt/GSK3 $\beta$ and Akt/Bcl-2 signaling pathways in nickel-transformed BEAS-2B cells. Int J Oncol 39: 1285-1294. [Crossref]

24. Son YO, Pratheeshkumar P, Roy RV, Hitron JA, Wang L, et al. (2015) Antioncogenic and Oncogenic Properties of Nrf2 in Arsenic-induced Carcinogenesis. J Biol Chem 290: 27090-27100. [Crossref]

25. Beezhold K, Liu J, Kan H, Meighan T, Castranova V, et al. (2011) miR-190mediated downregulation of PHLPP contributes to arsenic-induced Akt activation and carcinogenesis. Toxicol Sci 123: 411-420.

26. Pratheeshkumar P, Son YO, Divya SP, Wang L, Zhang Z, et al. (2016) Oncogenic transformation of human lung bronchial epithelial cells induced by arsenic involves ROS-dependent activation of STAT3-miR-21-PDCD4 mechanism. Sci Rep 6: 37227. [Crossref]

27. Avalle L, Pensa S, Regis G, Novelli F, Poli V (2012) STAT1 and STAT3 in tumorigenesis: A matter of balance. JAKSTAT 1: 65-72. [Crossref]
28. Shodeinde AL, Barton BE (2012) Potential use of STAT3 inhibitors in targeted prostate cancer therapy: future prospects. Onco Targets Ther 5: 119-125. [Crossref]

29. Carmeliet P, Jain RK (2000) Angiogenesis in cancer and other diseases. Nature 407 249-257. [Crossref]

30. Kim D, Dai J, Fai LY, Yao H, Son YO, et al. (2015) Constitutive activation of epidermal growth factor receptor promotes tumorigenesis of $\mathrm{Cr}(\mathrm{VI})$-transformed cells through decreased reactive oxygen species and apoptosis resistance development. $J$ Biol Chem 290: 2213-24. [Crossref]

31. Wang L, Chen F, Zhang Z, Chen G, Luo J, et al. (2012) Cancer stem cells in the mechanism of metal carcinogenesis. J Environ Pathol Toxicol Oncol 31: 245-263. [Crossref]

32. Sullivan JP, Minna JD, Shay JW (2010) Evidence for self-renewing lung cancer stem cells and their implications in tumor initiation, progression, and targeted therapy. Cancer Metastasis Rev 29: 61-72. [Crossref]

33. Mani SA, Guo W, Liao MJ, Eaton EN, Ayyanan A, et al. (2008) The epithelialmesenchymal transition generates cells with properties of stem cells. Cell 133: 704 715. [Crossref]

34. Wang L, Fan J, Hitron JA, Son YO, Wise JT, et al. (2016) Cancer Stem-Like Cells Accumulated in Nickel-Induced Malignant Transformation. Toxicol Sci 151(2):376-387.

35. Zhang T (2012) Autophagy Is a Cell Self-Protective Mechanism Against ArsenicInduced Cell Transformation. Toxicol Sci 130: 298.

36. Son YO, Pratheeshkumar P, Roy RV, Hitron JA, Wang L, et al. (2014) Nrf2/p62 signaling in apoptosis resistance and its role in cadmium-induced carcinogenesis. $J$ Biol Chem 289: 28660-28675. [Crossref]

Copyright: $(2018$ Liu Y. This is an open-access article distributed under the terms of the Creative Commons Attribution License, which permits unrestricted use, distribution, and reproduction in any medium, provided the original author and source are credited. 